\title{
Influence of Exogenously Applied Epibrassinolide and Putrescine on Protein Content, Antioxidant Enzymes and Lipid Peroxidation in Lycopersicon esculentum under Salinity Stress
}

\author{
Shummu Slathia ${ }^{1}$, Anil Sharma ${ }^{1}$, Sikander Pal Choudhary ${ }^{1,2}$ \\ ${ }^{1}$ Department of Botany, University of Jammu, Jammu, India; ${ }^{2}$ Department of Horticulture, Zhejiang University, Hangzhou, China. \\ Email: sikanderchowdhary@gmail.com
}

Received March 21 $1^{\text {st }}, 2012$; revised April 10 ${ }^{\text {th }}, 2012$; accepted April 25 $5^{\text {th }}, 2012$

\begin{abstract}
Brassinosteroids (BRs) and polyamines (PAs) are widely used to overcome abiotic stresses including salinity stress $(\mathrm{NaCl})$ in plants. In the present investigation, we evaluated the co-application efficacy of 24-epibrassinolide (EBR, a highly active BR) and putrescine (Put, a PA) on the $\mathrm{NaCl}$ stress $(75 \mathrm{mM}$ and $150 \mathrm{mM}$ ) tolerance of Lycopersicon esculentum L. cv. kuber geeta plants. A small rise in protein content was recorded under salinity stress in comparison with untreated control. The $\mathrm{NaCl}$ stress was found to significantly enhance the activities of guaiacol peroxidase (GPOX) and superoxide dismutase (SOD); while decline in catalase (CAT) activity was recorded when compared with the untreated control. Salinity stress both at $75 \mathrm{mM}$ and $150 \mathrm{mM}$ was able to cause significant membrane damage as evidenced by an increase in the level of malondialdehyde (MDA) content over untreated control. The EBR and Put co-applications were able to improve protein content in $\mathrm{NaCl}$ stressed plants over only $\mathrm{NaCl}$ stressed plants. The co-applications of EBR and Put were able to significantly enhance the activities of CAT, SOD and GPOX in L. esculentum under salinity stress (75 $\mathrm{mM}$ and $150 \mathrm{mM}$ ) when compared with $\mathrm{NaCl}$ stressed plants alone. Major decline in the MDA level recorded for EBR and Put co-applications under $\mathrm{NaCl}$ stress revealed reduced membrane damages when compared with $\mathrm{NaCl}$ stressed plants alone. Our findings provide evidence that EBR and Put co-applications are effective in amelioration of $\mathrm{NaCl}$ stress in L. esculentum. Thus co-application potential of EBR and Put may acts an eco-friendly approach towards $\mathrm{NaCl}$ stress mitigation in economically important crops.
\end{abstract}

Keywords: Lycopersicon esculentum; Brassinosteroids; Polyamines; Salinity Stress

\section{Introduction}

Salinity stress is one of the major agricultural constraint limiting plant growth and development over the world [1]. Approximately $10 \%$ of the total land surface is salt affected and about 10 million hectare of agricultural land is lost annually due to salinisation and water logging [2]. The process of salinisation is both natural and man made, with former caused by elevation of capillary water level and subsequent evaporation of saline ground water leaving behind the salts on the soil surface. However man made salinisation is more prevalent in the less irrigated areas of the arid regions [3]. The overaccumulation of water soluble salts, like sodium chloride $(\mathrm{NaCl})$, sodium carbonate $\left(\mathrm{Na}_{2} \mathrm{CO}_{3}\right)$ and calcium chloride $\left(\mathrm{CaCl}_{2}\right)$ results in saline soils [4]. High concentration of $\mathrm{NaCl}$ in saline soil subsequently sets up a severe competition between $\mathrm{Na}^{+}$and $\mathrm{K}^{+}$ions which in turn disturbs the common transport system of plant roots [5]. Excess of salts mainly affects through ion imbalance and imposition of hyperosmotic stress in plant systems that ultimately leads to the production of reactive oxygen species (ROS) [6]. Furthermore salt stress also induces water stress through osmotic stress, specific ion toxicity and oxidative damages $[7,8]$. The ROS such as $\mathrm{O}_{2}^{-}, \mathrm{H}_{2} \mathrm{O}_{2}$ and $\mathrm{OH}$. produced under salt stress have been shown to cause significant damage to lipids, carbohydrates and nucleic acids, thereby driving cell towards senescence or programmed cell death [9]. Salt stress generated ROS also induce membrane damages by attacking the polyunsaturated fatty acids to produce lipid hydroperoxides, thereby increasing membrane leakage and secondary damages to the membrane proteins, DNA and RNA [6]. Salt stress impede vital physiological processes of plant growth and development such as seed germination, seedling growth, seed vigor, vegetative growth, flowering and fruit set [10]. Disturbed ability of water uptake and reduced growth of plant roots has also been observed under salt 
stress [4]. Tomato is one of the most important fleshy fruit with high economic value. Salt stress has been shown to decrease dry matter production and nitrogen uptake in tomato plants under salinity stress [11]. The tomato plants grown under salt stress have been shown to have low dry matter, fruit weight and relative water content [12]. Another report also observed significant reduction in the photosynthetic pigments and total soluble protein in tomato plants grown under salt stress [13].

In order to combat environmental adversities like salt stress, plants have developed a unique defense system composed of antioxidants and antioxidant enzymes [14]. The implication of cytokinins, ethylene and abscisic acid in salt stress management among plants is widely reported [15]. Among other plant growth regulators, brassinosteroids (BRs) role in plant stress responses has been widely documented [16-19]. In general BRs are polyhydroxylated derivatives of cholestane with wide distribution in the plant kingdom. They regulate a diverse array of biological processes such as cell division, seed germination, vascular differentiation, growth and reproductive organ development [19]. They have been reported to protect plants from various stresses like water stress [20], temperature stress [21] and salt stress [22-24]. The pleiotropic effects of BRs have been shown to depend at least in part on their interactions with other plant hormones such as auxins, abscisic acid and ethylene which modulate various plant stress responses [19].

Polyamines (PAs) are small aliphatic nitrogenous compounds present in all the living organisms [25]. Among PAs, the putrescine (Put), cadaverine (Cad), spermidine (Spd) and spermine (Spm) are known to play significant roles in the regulation of cell division, embryogenesis, reproductive organ development, root growth and abiotic stresses responses [26]. Variations in PA contents have been associated with several types of stresses e.g. heavy metal stress [16-18,27], chilling stress [28], water stress [29] and salinity stress [30-33].

The individual application of BRs and PAs has been shown to improve salt stress tolerance of plants however their co-application efficacy still needs to be tested. Keeping that in mind the present investigation determined the exogenous co-application potential of BRs and PAs in salt stress management of tomato plants. We aimed to evaluate the co-application effects of BRs and PAs in salt stress tolerance of Lycopersicon esculentum. Our results showed that co-application of 24-epibrassinolide (EBR) and Put have more pronounced effects in the amelioration of salinity stress in tomato.

\section{Material and Methods}

\subsection{Plant Material and Treatments}

The present investigation was carried out on L. esculentum
L. cv. Kuber Geeta plants. Certified seeds of L. esculenttum were procured from Punjab Agricultural University, Ludhiana, India. Seeds were surface sterilized with $0.01 \%$ Sodium hypochlorite. The plantlets were raised from the sterilized seeds in the pots. Plantlets $(10 \mathrm{~cm}$ in height $)$ were transferred after 10 days to other pots with one plantlet in each pot. After attaining a specified height $(35-40 \mathrm{~cm})$ at 35-40-d-old plants were subjected to $\mathrm{NaCl}$ stress with/ without EBR and putrescine (Put) in various combinations by foliar spray method. About 20-d after application of EBR and Put with/or without $\mathrm{NaCl}$ stress the samples were harvested to perform the analysis. The effects of EBR and Put co-applications on protein content, antioxidant enzyme activities and lipid peroxidation under control conditions (no salinity stress) were also investigated in tomato plants.

\subsection{Treatments}

The leaves of tomato plants were subjected to the following treatments:

\subsubsection{Salt Treatment}

The salinity stress $(\mathrm{NaCl})$ in the present investigation was generated by the application of $\mathrm{NaCl}$ at a concentration of $75 \mathrm{mM}$ and $150 \mathrm{mM}$ to 40 -d-old tomato plants.

\subsubsection{Brassinosteroid Treatment}

The brassinosteroid used in present study was EBR. Different concentrations of EBR were prepared from the stock solution of $10^{-5} \mathrm{M}$, previously prepared from $10^{-3}$ M EBR prepared in DMSO (Dimethyl sulphoxide). The concentration of $10^{-10}$ and $10^{-8} \mathrm{M}$ EBR were prepared by serial dilution of the parent stock solution.

\subsubsection{Polyamine Treatment}

The polyamine used in present investigation was Putrescine dihydrochloride (Put). The Put concentration (1 $\mathrm{mM}$ ) used in the present experiment was prepared by serial dilution of parent stock solution of $10 \mathrm{mM}$ prepared in double distilled water.

\subsection{Preparation of Plant Extract}

Leaf tissue ( $0.5 \mathrm{~g}$ fresh weight, $\mathrm{FW})$ was homogenized in $3 \mathrm{ml}$ of $0.1 \mathrm{M}$ potassium phosphate buffer in a pre-chilled pestle and mortar, centrifuged at $15,000 \mathrm{~g}$ for $20 \mathrm{~min}$. The supernatant was used for the estimation of protein content and antioxidant enzyme activities.

\subsection{Protein Estimation}

The protein content was estimated according to method of Lowry et al. [34]. 


\subsection{Guaiacol Peroxidase (GPOX, EC 1.11.1.7)}

The GPOX activity was estimated as per method of Putter [35]. In brief, reaction mixture consisted of $3 \mathrm{ml}$ of phosphate buffer, $50 \mu \mathrm{l}$ guaiacol solution, $100 \mu \mathrm{l}$ enzyme extract and $30 \mu 1$ of $\mathrm{H}_{2} \mathrm{O}_{2}$ solution. The rate of the formation of oxidized guaiacol product was followed spectrophotometrically at $436 \mathrm{~nm}$ using UV/VIS absorption Spectrophotometer (Specord M-40, Jena, Germany).

\subsection{Catalase (CAT, EC 1.11.1.6)}

The activity of CAT was estimated according to the method developed by Aebi [36]. The reaction mixture consisted of $1.5 \mathrm{ml}$ of potassium phosphate buffer (50 $\mathrm{mM}), 1.2 \mathrm{ml}$ of $\mathrm{H}_{2} \mathrm{O}_{2}(150 \mathrm{mM})$ and $30 \mu \mathrm{l}$ of enzyme extract. The change in the absorbance was read at $240 \mathrm{~nm}$ using UV/VIS absorption Spectrophotometer (Specord M40, Jena, Germany).

\subsection{Superoxide Dismutase (SOD, EC 1.15.1.1)}

The SOD activity was determined as per method proposed by Kono [37]. About $1.8 \mathrm{ml}$ sodium carbonate buffer, $750 \mu \mathrm{l}$ nitroblue tetrazolium (NBT) and $150 \mu \mathrm{l}$ Triton $\mathrm{x}-100$ were taken in a cuvette. The reaction was initiated by the addition of $150 \mu 1$ of hydroxylamine hydrochloride, followed by incubation for $2 \mathrm{~min}$ and addition of 70 $\mu 1$ enzyme extract. This reaction mixture was taken in a cuvette and inhibition in the rate of reduction of NBT was recorded at $540 \mathrm{~nm}$ using UV/VIS absorption Spectrophotometer (Specord M-40, Jena, Germany).

\subsection{Lipid Peroxidation}

Lipid peroxidation was estimated according to the method of Heath and Packer [38]. Tomato leaves (0.5 g FW) supplied with EBR/and or Put with/or without salinity stress were homogenized in $3 \mathrm{ml}$ of $0.1 \%$ trichloro acetic acid (TCA). The samples were centrifuged at $10,000 \mathrm{~g}$ for 5 min and supernatants were treated with $3 \mathrm{ml}$ of thiobarbutric acid (TBA, prepared in TCA). The solution was kept in water bath at $95^{\circ} \mathrm{C}$ for $30 \mathrm{~min}$ and later cooled immediately to stop the reaction. The readings were taken spectrophotometrically at 532 and $600 \mathrm{~nm}$ and MDA content was determined after subtracting the non specific absorbance at $600 \mathrm{~nm}$ from the absorbance value taken at $532 \mathrm{~nm}$.

\subsection{Statistical Analysis}

All the experiments were performed in triplicates. The data shown are the means of three replicate experiments along with standard error $(n=3)$. One-way analysis of variance (ANOVA) was carried out and data were presented at $\mathrm{p}<0.05$. All the statistical calculations were performed using Sigma Stat 3.5.

\section{Results and Discussion}

\subsection{Protein Content}

The present study revealed enhancing effects of salt stress on the protein content of the tomato leaves in comparison to untreated control. The $\mathrm{NaCl}$ stress at $(75 \mathrm{mM})$ caused more pronounced effects than $150 \mathrm{mM} \mathrm{NaCl}$ in terms of protein content in comparison to untreated control (Figure 1). The increase in protein content under salinity stress and its further improvement upon supplementation of EBR and Put in various combination with/or without salt stress suggests synergistic interactions among EBR and Put in amelioration of salinity stress and under control conditions. The present observations can be supported by the findings of Arora et al. [22], that BR application could enhance protein content in Zea mays seedlings under salinity stress. The promoting effects of BRs on the protein content could be attributed to activation of transcription and translational processes of specific stress tolerance genes [39]. The enhanced synthesis of proteins in rice seedlings treated with EBR under salt stress had also been reported by Ozdemir [40]. The protective role of EBR against $\mathrm{NaCl}(0.5 \mathrm{M})$ stress on barley leaf cell ultra-structure and nucleus and chloroplast degradation were recorded by [41].

\subsection{Antioxidative Enzymes}

The present study revealed that application of $\mathrm{NaCl}$ stress

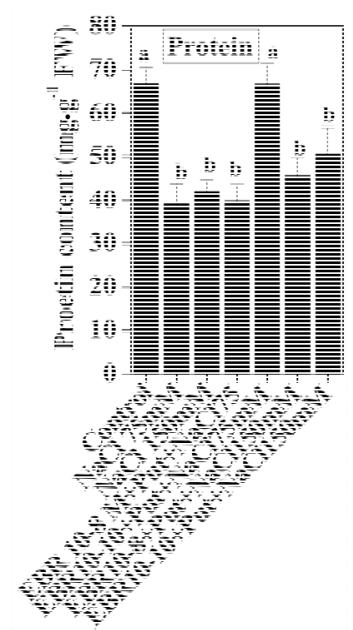

(a)

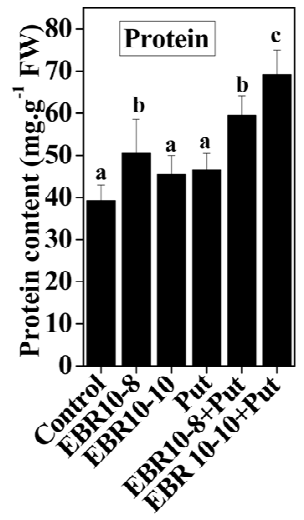

(b)
Figure 1. Effects of EBR and/or Put on protein content of 60-d-old tomato plant leaves grown with (a) or without (b) salt $(75 \mathrm{mM}$ or $150 \mathrm{mM})$ stress. Data are presented as mean \pm SE. Different superscripted letters $(a, b$, and $c)$ indicate significant difference from each other in all combinations (Tukey's test, $\mathbf{p}<\mathbf{0 . 0 5}$ ). 
(75 and $150 \mathrm{mM}$ ) was able to enhance the activities of SOD and GPOX; but reduced activity of CAT was observed when compared to untreated control (Figures 2-4). Similar results were observed by Alghaleh et al. [42], who showed that two species of Salicornia (persica and europea) when treated with different concentrations of $\mathrm{NaCl}$ showed increase in the activities of SOD, CAT and GPOX. Hernandez and Almansa [43] also observed an increase in the activities of SOD and glutathione reductase in Pisum sativum under salinity stress. Seedlings of Jatropha curcas exposed to salt stress showed an increased activity of SOD [1]. Enhanced activities of SOD, CAT and POX in Cassia angustifolia under salt stress had been reported by Agarwal and Pandey [44-46].

Application of EBR and Put at various concentrations to salt stressed plants considerably enhanced the activities of antioxidative enzymes as compared to only salt stressed plants thereby conferring $\mathrm{NaCl}$ stress tolerance in tomato plants. The findings could be supported by the observations that PAs could enhance the activities of ascobate peroxidase, CAT and SOD in cucumber under salt stressed and controlled conditions [47]. Improved activities of antioxidant enzymes such as SOD, POD, CAT, GR and APOX and reduced lipid peroxidation had been observed upon BR application to Zea mays seedlings under $\mathrm{NaCl}$ stress [22]. The co-application of EBR and Put to $\mathrm{NaCl}$ stressed plants showed enhanced activities of antioxidant enzymes over $\mathrm{NaCl}$ stressed plants alone. The co-application of EBR and Put to unstressed plants also revealed altered activities of CAT, GPOX and SOD enzymes when compared with untreated control. The present study thus revealed synergistic effects of EBR and Put co-application in the improvement of antioxidant enzymes activities under salt stress and controlled conditions (Figures 2-4).

\subsection{Lipid Peroxidation}

Salt stress was observed to damage cell membrane as indicated by high concentration of MDA content observed in salt stressed plants when compared with untreated control. Salt stress has been shown to enhance lipid peroxidation in Catharanthus roseus suspension cells [45]. Similarly, Koca et al. [46] observed increased lipid peroxidation in sesame cultivars subjected to salinity stress. The EBR and Put co-application without stress also showed decline in MDA content when compared with untreated control. The combination of EBR and Put was observed to reduce MDA content significantly when compared to only $\mathrm{NaCl}$ stressed plants. Lipid peroxidation is used as index of oxidative damages caused by various environmental stresses in plants. Such that ROS species react with lipids and leads to formation of highly active peroxyl radical, which in turn starts chain propagation re- action of lipid peroxidation. Decline in MDA content brought by EBR and Put application could be associated with enhanced activities of CAT, GPOX and SOD enzymes which in turn scavenge ROS species and hereby reducing the negative impact of ROS on membrane damage (Figure 5).

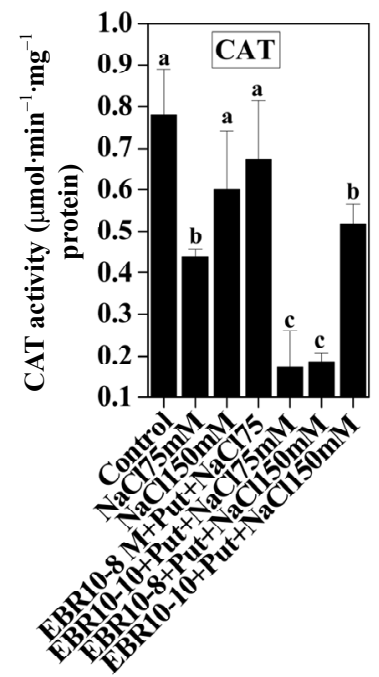

(a)

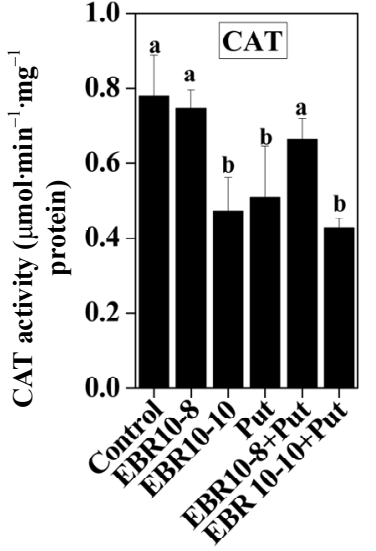

(b)
Figure 2. Effects of EBR and/or Put on CAT activity of 60-d-old tomato plant leaves grown with (a)/or without (b) salt $(75 \mathrm{mM}$ or $150 \mathrm{mM})$ stress. Data are presented as mean \pm SE. Different superscripted letters $(a, b$ and $c)$ indicate significant difference from each other in all combinations (Tukey's test, $\mathbf{p}<\mathbf{0 . 0 5}$ ).

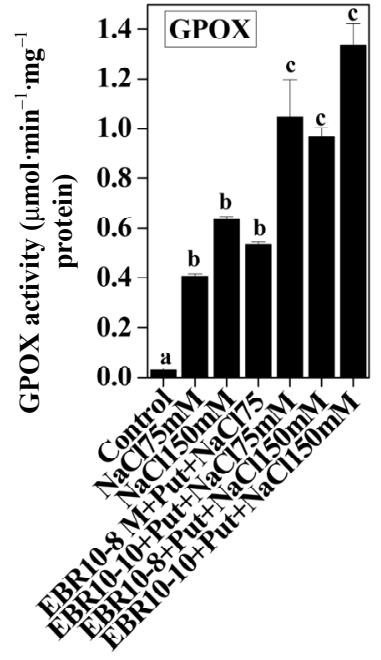

(a)

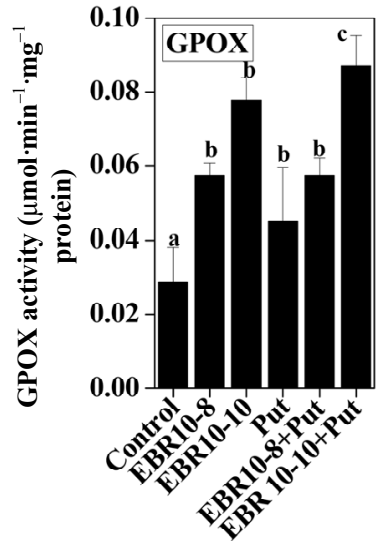

(b)
Figure 3. Effects of EBR and/or Put on GPOX activity of 60-d-old tomato plant leaves grown with (a) or without (b) salt (75 $\mathrm{mM}$ or $150 \mathrm{mM})$ stress. Data are presented as mean \pm SE. Different superscripted letters $(a, b$ and $c)$ indicate significant difference from each other in all combinations (Tukey's test, $\mathbf{p}<\mathbf{0 . 0 5}$ ). 


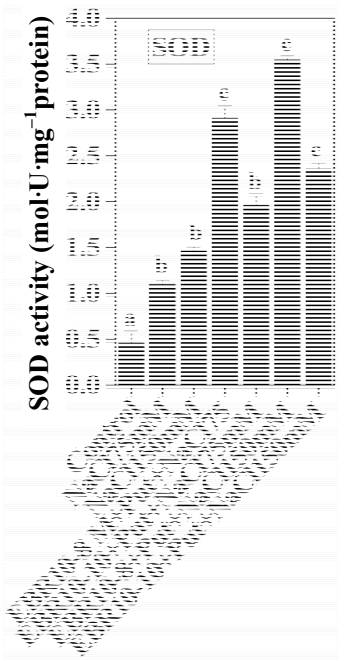

(a)

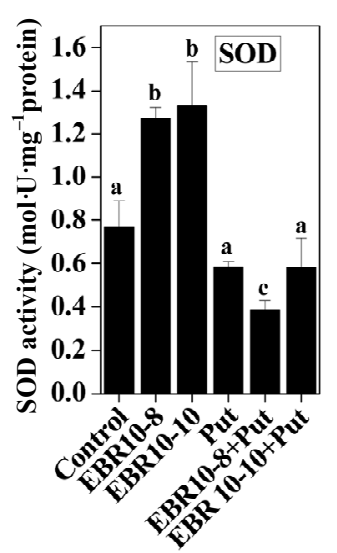

(b)
Figure 4. Effects of EBR and/or Put on SOD activity of 60d-old tomato plant leaves grown with (a) or without (b) salt $(75 \mathrm{mM}$ or $150 \mathrm{mM})$ stress. Data are presented as mean \pm SE. Different superscripted letters $(a, b$ and $c)$ indicate significant difference from each other in all combinations (Tukey's test, $\mathrm{p}<\mathbf{0 . 0 5}$ ).

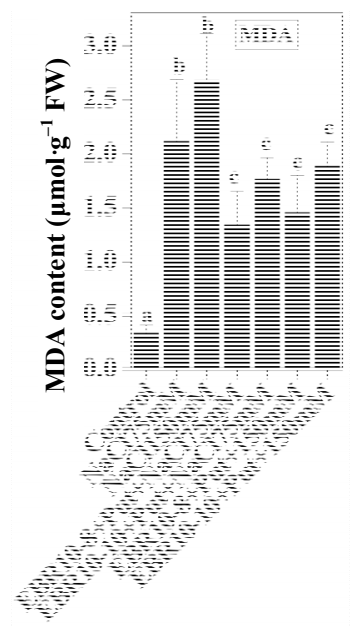

(a)

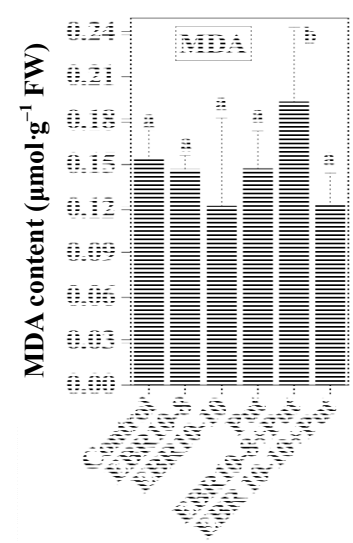

(b)
Figure 5. Effects of EBR and/or Put on MDA content of 60-d-old tomato plant leaves grown with (a) or without (b) salt $(75 \mathrm{mM}$ or $150 \mathrm{mM})$ stress. Data are presented as mean \pm SE. Different superscripted letters $(a, b$ and $c)$ indicate significant difference from each other in all combinations (Tukey's test, $\mathbf{p}<0.05$ ).

\section{Conclusion}

The findings presented here suggest that co-application of EBR and Put is more beneficial in $\mathrm{NaCl}$ stress mitigation in tomato plants than their individual treatments. The findings have huge agricultural implication with focus on $\mathrm{NaCl}$ stress amelioration using bio-friendly and cost effective strategies.

\section{REFERENCES}

[1] S. Gao, C. Ouyang, S. Wang, Y. Xu, L. Tang and F. Chen, "Effects of Salt Stress on Growth, Antioxidant Enzyme and Phenylalanine Ammonia-Lyase Activities in Jatropha curcas L. Seedlings," Plant Soil Environment, Vol. 5, No. 9, 2008, pp. 373-381.

[2] H. Monirifar and M. Barghi, "Identification and Selection for Salt Tolerance in Alfalfa (Medicago sativa L.) Ecotypes via Physiological Traits," Notulae Scientia Biologicae, Vol. 1, No. 1, 2009, pp. 63-66.

[3] S. Supper, "Verstecktes Wasser," Sustainable Austria No. $25,2003$.

[4] K. Nawaz, K. Hussain, A. Majeed, K. Farah, S. Afghan and K. Ali, "Fatality of Salt Stress to Plants: Morphological Physiological and Biochemical Aspects," African Journal of Biotechnology, Vol. 9, No. 34, 2010, pp. 5475-5480.

[5] S. Yokoi, A. Bressan and P. M. Hasegawa, "Salt Stress Tolerance of Plants," JIRCAS Working Report, 2002, pp. 25-33.

[6] P. Ahmad, C. A. Jallel, M. M. Arooz and G. Nabi, "Generation of ROS and Non Enzymatic Antioxidants during Abiotic Stress in Plants," Botany Research International, Vol. 2, No. 1, 2009, pp. 11-20.

[7] R. Munns, "Comparative Physiology of Salt and Water Stress," Plant, Cell and Environment, Vol. 25, No. 2, 2002, pp. 239-250. doi:10.1046/j.0016-8025.2001.00808.x

[8] K. Siringam, N. Juntawang, S. Cha-Um and C. Kirdmaner, "Salt Stress Induced Ion Accumulation, Ion Homeostasis, Membrane Injury and Sugar Contents in Salt-Sensitive Rice (Oryza sativa L. spp. indica) Roots under Isoosmotic Conditions," African Journal of Biotechnology, Vol. 10, No. 8, 2011, pp. 1340-1346.

[9] M. Valko, D. Leibfritz, J. Moncol T. D. Mark, M. C. Milan and J. Telser, "Free Radicals and Antioxidants in Normal Physiological Functions and Human Disease," The International Journal of Biochemistry and Cell Biology, Vol. 39, No. 1, 2007, pp. 44-84. doi:10.1016/j.biocel.2006.07.001

[10] R. K. Sairam and A. Tyagi, "Physiology and Molecular Biology of Salinity Stress Tolerance in Plants," Current Science, Vol. 86, No. 3, 2004, pp. 407-412.

[11] S. A. Al-Rawahy, J. L. Stroehlein and M. Pessarakli, "Effect of Salt Stress on Dry Matter Production and Nitrogen Uptake by Tomatoes," Journal of Plant Nutrition, Vol. 13, No. 5, 1990, pp. 567-577. doi:10.1080/01904169009364100

[12] A. L. Tuna, C. Kaya, M. Ashraf, H. Altunlu, I. Yokas and B. Yagmono, "The Effects of Calcium Sulphate on Growth, Membrane Stability and Nutrient Uptake of Tomato Plants Grown under Salt Stress," Environmental and Experimental Botany, Vol. 59, No. 2, 2007, pp. 173-178. doi:10.1016/j.envexpbot.2005.12.007

[13] Z. B. Doganler, K. Demir, H. Basak and I. Gul, “ Effect of Salt Stress on Pigment and Total Soluble Protein Contents of Three Different Tomato Cultivars," African Journal of Agricultural Research, Vol. 5, No. 15, 2010, pp. 2056-2065. 
[14] C. M. Andre, L. Yvan and E. Daniele, "Dietary Antioxidants and Oxidative Stress from a Human and Plant Perspective: A Review," Current Nutrition and Food Science, Vol. 6, No. 1, 2010, pp. 2-12. doi:10.2174/157340110790909563

[15] J. R. Torres-García, J. A. Escalante-Estrada, M. T. Rodríguez-González, C. Ramírez-Ayala and D. Martínez-Moreno, "Exogenous Application of Growth Regulators in Snap Bean under Water and Salinity Stress," Journal of Stress Physiology and Biochemistry, Vol. 5, No. 3, 2009, pp. 13-21.

[16] S. P. Choudhary, R. Bhardwaj, B. D. Gupta, P. Dutt, R. K. Gupta, S. Biondi and M. Kanwar, "Epibrassinolide Induces Changes in Indole-3-Acetic Acid, Abscisic Acid and Polyamine Concentrations and Enhances Antioxidant Potential of Radish Seedlings under Copper Stress," Physiologia Plantarum, Vol. 140, No. 3, 2010, pp. 280-296.

[17] S. P. Choudhary, M. Kanwar, R. Bhardwaj, B. D. Gupta and R. K. Gupta, "Epibrassinolide Ameliorates Cr(VI) Stress via Influencing the Levels of Indole-3-Acetic Acid, Abscisic Acid, Polyamines and Antioxidant System of Radish Seedlings," Chemosphere, Vol. 84, No. 5, pp. 592-600. doi:10.1016/j.chemosphere.2011.03.056

[18] S. P. Choudhary, M. Kanwar, R. Bhardwaj, J. Q. Yu and L. S. Tran, "Chromium Stress Mitigation by PolyamineBrassinosteroid Application Involves Phytohormonal and Physiological Strategies in Raphanus sativus L.," PLOS ONE, Vol. 7, No. 3, 2012, p. e33210. doi:10.1371/journal.pone.0033210

[19] G. E. Gudesblat and E. Russinova, "Plants Grow on Brassinosteroids," Current Opinion in Plant Biology, Vol. 14, No. 5, 2011, pp. 530-537. doi:10.1016/j.pbi.2011.05.004

[20] K. R. Li and C. H. Feng, "Effects of Brassinolide on Drought Resistance of Xanthocerous sorbifolia Seedlings under Water Stress," Acta Physiologiae Plantarum, Vol. 33, No. 4, 2011, pp. 1293-1300. doi:10.1007/s11738-010-0661-0

[21] J. Honnerova, O. Rothova, D. Hola, M. Kocova, L. Kohout and M. Kvasnica, "The Exogenous Application of Brassinosteroids to Zea mays (L.) Stressed by Long Term Chilling Does Not Affect the Activities of Photosystem 1 or 2," Journal of Plant Growth Regulation, Vol. 29, No. 4, 2010, pp. 500-505. doi:10.1007/s00344-010-9153-0

[22] N. Arora, P. Sharma, R. Bhardwaj and H. K. Arora, "Effect of 28-Homobrassinolide on Growth, Lipid Peroxidation and Antioxidative Enzyme Activities in Seedlings of Zea mays L. under Salinity Stress," Acta Physiologiae Plantarum, Vol. 30, No. 6, 2008, pp. 833-839. doi:10.1007/s11738-008-0188-9

[23] V. K. Divi, T. Rahman and P. Krishna, "Brassinosteroids Mediated Stress Tolerance in Arabidopsis Shown Interactions with Ascorbic Acid, Ethylene and Salicylic Acid Pathways," BMC Plant Biology, Vol. 10, 2010, p. 151. doi:10.1186/1471-2229-10-151

[24] S. I. M. Houimli, M. Denden and B. D. Mouhandes, "Effect of 24-Epibrassinolide on the Growth, Chlorophyll, Electrolyte Leakage and Proline by Pepper Plants under $\mathrm{NaCl}$ Stress," EurAsian Journal of Biosciences, Vol. 4,
2010, pp. 96-104. doi:10.5053/ejobios.2010.4.0.12

[25] A. Tassoni, M. Franceschetti and N. Bagni, "Polyamines and Salt Stress Response and Tolerance in Arabidopsis thaliana Flowers," Plant Physiology and Biochemistry Vol. 46, No. 5-6, 2008, pp. 607-613. doi:10.1016/j.plaphy.2008.02.005

[26] S. S. Hussain, M. Ali, M. Ahmad and K. H. Siddique, "Polyamines: Natural and Engineered Abiotic and Biotic Stress Tolerance in Plants," Biotechnology Advances, Vol. 29, No. 3, 2011, pp. 300-311. doi:10.1016/j.biotechadv.2011.01.003

[27] H. Zhao and H. Yang, "Exogenous Polyamines Alleviate Lipid Peroxidation Induced by Cadmium Chloride Stress in Malus hupehensis," Scientia Horticulturae, Vol. 116, No. 4, 2008, pp. 442-447. doi:10.1016/i.scienta.2008.02.017

[28] T. Cakmak and O. Atici, "Effects of Putrescine and Low Temperature on the Apoplastic Antioxidant Enzymes in the Leaves of Two Wheat Cultivars," Plant Soil Environment, Vol. 55 No. 8, 2009, pp. 320-326.

[29] F. Muhammad, W. Abdul and D.-J. Lee, "Exogenously Applied Polyamines Increase Drought Resistance by Improving Leaf Water Status, Photosynthesis and Membrane Properties," Acta Physiologiae Plantarum, Vol. 31, No. 5, 2009, pp. 937-945. doi:10.1007/s11738-009-0307-2

[30] I. M. Zeid, "Response of Bean (Phaseolus vulgaris) to Exogenous Putrescine Treatment under Salinity Stress," Pakistan Journal of Biological Sciences, Vol. 7, No. 2, 2004, pp. 219-225. doi:10.3923/pjbs.2004.219.225

[31] F. Mutlu and S. Bozcuk, "Salinity Induced Changes of Free and Bound Polyamine Levels in Sunflower (Helianthus annus L.) Roots Differing in Salt Tolerance," Pakistan Journal of Biological Sciences, Vol. 39, No. 4, 2007 , pp. 1091-1102.

[32] K. Yamaguchi, Y. Takahashi, T. Berberich, A. Imai, A. Miyazaki, T. Takahashi, A. Michael and T. Kusano, "The Polyamine Spermine Protects against High Salt Stress in Arabidopsis thaliana," Federation of European Biochemical Societies, Vol. 580, No. 30, 2006, pp. 6783-6788.

[33] L. Rebecca, D. Soni and S. Anbuselvi, "Effect of Exogenous Spermidine on Salinity Tolerance with Respect to Seed Germination," International Journal of Applied Agricultural Research, Vol. 5, No. 2, 2010.

[34] O. H. Lowry, N. J. Rosebrough and A. L. Farr, "Protein Measurement with the Folin Phenol Reagent," Journal of Biological Chemistry, Vol. 193, No. 1, 1951, pp. 265-275.

[35] J. Putter, "Peroxidase," In: H. U. Bergmeyer, Ed., Methods of Enzymatic Analysis, Verlag Chemie, Weinhan, 1974, pp. 685-690.

[36] H. E. Aebi, “Catalase,” In: Methods of Enzymatic Analysis, Verlag Chemie, Weinhan, Vol. 4, 1983, pp. 273-282.

[37] Y. Kono, "Generation of Superoxide Radical during Autoxidation of Hydroxylamine and an Assay for Superoxide Dismutase," Archives of Biochemistry and Biophysics, Vol. 186, No. 1, 1978, pp. 189-195. doi:10.1016/0003-9861(78)90479-4 
[38] R. L. Heath and L. Packer, "Photoperoxidation in Isolated Chloroplasts. I. Kinetics and Stoichiometry of Fatty Acid Peroxidation," Archives of Biochemistry and Biophysics, Vol. 125, No. 1, 1968, pp. 189-198. doi:10.1016/0003-9861(68)90654-1

[39] S. Kagale, U. K. Divi, J. E. Krochko, W. A. Keller and P. Krishna, "Brassinosteroids Confer Resistance to Arabidopsis thaliana and Brassica napus to a Range of Abiotic Stresses," Planta, Vol. 225, No. 2, 2007, pp. 353-364. doi:10.1007/s00425-006-0361-6

[40] F. Ozdemir, M. Bor, T. Demiral and I. Turkan, "Effects of 24-Epibrassinolide on Seed Germination, Seedling Growth, Lipid Peroxidation, Proline Content and Antioxidative System of Rice (Oryza sativa L.) under Salinity stress," Plant Growth Regulation, Vol. 42, No. 3, 2004, pp. 203-211. doi:10.1023/B:GROW.0000026509.25995.13

[41] O. N. Kulaeva, E. A. Burkhanova, A. B. Fedina, V. A. Khokhlova, G. A. Bokebayeva, H. M. Bokebayeva and G. Adam, "Effect of Brassinosteroids on Protein Synthesis and plant Cell Ultrastructure under Stress Conditions," American Chemical Society, Vol. 474, No., 1991, pp. 141-155.

[42] M. Aghaleh, V. Niknam, H. Ebrahimzadeh and K. Razavi, "Effect of Salt Stress on Physiological and Antioxidant Responses in Two Species of Salicornia (S. persica and S. europaea)," Acta Physiologiae Plantarum, Vol. 33, No. 4, 2011, pp. 1261-1270.

\section{doi:10.1007/s11738-010-0656-x}

[43] J. A. Hernandez and M. S. Almansa, "Short Term Salt Stress on Antioxidant Systems and Leaf Water Relations of Pea Leaves," Physiologia Plantarum, Vol. 115, No. 2, 2002, pp. 251-257. doi:10.1034/j.1399-3054.2002.1150211.x

[44] S. Agarwal and V. Pandey, "Antioxidant Enzyme Responses to $\mathrm{NaCl}$ Stress in Cassia angustifolia," Biologia Plantarum, Vol. 48, No. 4, 2004, pp. 555-560. doi:10.1023/B:BIOP.0000047152.07878.e7

[45] S. Elkahoui, J. A. Hernandez, C. Abdelly, G. Rachid and L. Ferid, "Effect of Salt on Lipid Peroxidation and Antioxidant Enzyme Activities of Catharanthus roseus Suspension Cell," Plant Science, Vol. 168, No. 3, 2010, pp. 607-613.

[46] H. Koca, M. Bor, F. Ozdemir and I. Turkan, "The Effect of Salt Stress on Lipid Peroxidation, Antioxidative Enzymes and Proline Content of Sesame Cultivars," Environmental and Experimental Botany, Vol. 60, No. 3, 2007, pp. 344-351. doi:10.1016/j.envexpbot.2006.12.005

[47] J.-Ju. Duan, S.-R. Guo, Y.-Y. Kang and Y.-S. Jiao, "Effects of Exogenous Spermidine on Polyamine Content and Antioxidant System in Roots of Cucumber under Salinity Stress," Journal of Ecology and Rural Environment, Vol. 4, No. 4, 2007, pp. 11-17. 